\title{
Literature Review: Effect of Cooperative Learning on Intrinsic Motivation
}

\author{
Christopher Lynn Brown \\ Department of Education, Eastern New Mexico University, Portales, NM, USA
}

\begin{abstract}
The purpose of this literature review is to understand what cooperative learning is, how it affects student intrinsic motivation, identifying some barriers to implementing it, and examine reasons for its failure in some classrooms. This literature review analyzed and critiqued nine empirical studies from around the world and discussed one foundational study, which were all located using Eastern New Mexico University's Golden Library and professor suggestion. The findings of this literature review show that cooperative learning has a positive impact on student intrinsic motivation, but has problems being appropriately implemented and fails in certain situations. The implications that can be drawn from this author's research are that cooperative learning is not merely group work, that cooperative learning has a positive impact on student intrinsic motivation, that student age may affect the ability to utilize cooperative learning, that teacher training is desirable in implementing cooperative learning, and that student preparation all have a direct influence on the success or failure of cooperative learning in the classroom.
\end{abstract}

Keywords: cooperative learning; intrinsic motivation; teaching techniques.

\section{INTRODUCTION}

$\mathrm{T}$ eaching is no longer a lecturer reciting knowledge or lecturing at students who are expected to memorize facts and information and then prove their memorization on a close ended, multiple choice question test. For nearly 200 years, a great deal of research has been conducted in the field of education (Frey, 2018) in the hopes of helping teachers teach better and learners learn more efficiently. As the years have passed, attention has shifted from being teacher-focused to student-focused pedagogy. There are many theories, techniques, and structures which have been proposed by researchers throughout the past two centuries, some with more credence and credibility than others. Of particular interest in this literature review is the research and development of cooperative learning (CL) and Self-Determination Theory (SDT), in particular, intrinsic motivation (IM).

IM should be of interest to every educator, as that is what "drives" learners to learn effectively, consistently, and enduringly - that is, it creates the desire for learners to learn for its own sake, as well as become lifelong learners (Crow, 2006). The numerous benefits of CL have been demonstrated in studies around the world, one major benefit being that it helps close the achievement gap (Ghodbane \& El Achachi, 2019). Understanding that CL positively impacts IM can help motivate educators to learn and utilize $\mathrm{CL}$ in their classrooms.

\section{COOPERATIVE LEARNING}

Although the origins of the concept of CL has been linked to the Talmud, Quintillion, and Seneca, even if only by mere statements, or more recently, Deutsch (1949), as it is understood today, CL is namely attributed to Slavin (1980), and Johnson and Johnson (1984). Although their research was not collaborative, their combined theories form the seminal concept of CL. The reason CL has become such an interest are the reported learner benefits.

A brief list of the research-proven benefits of CL include an increase in students' self-esteem, satisfaction, mastery; the development of cooperation, confidence, social interaction, leadership, expectations; the reduction of classroom and test anxiety (Panitz, 1999). These benefits have been observed at all levels of education: primary, secondary, and tertiary. One may wonder how it is possible for CL to accomplish all this. The structure of CL activities and instruction are what have produced the above-listed benefits. Johnson and Johnson (2007) established the five expectations of CL to include the following:

- Positive interdependence (one cannot win unless everyone wins)

- Individual accountability (everyone must contribute)

- Interpersonal skills (communication, problem solving, etc.)

- Face-to-face interaction

- Reflection (evaluating and team) (Baumgardner, 2015).

Although group work and pair work can be beneficial in the classroom, they only include interpersonal skills and face-toface interaction. In comparison, by CL's design, positive interdependence, individual accountability, and reflection become a part of the learning process. Involving all five aspects in the learning process is what makes CL an effective teaching technique.

\section{INTRINSIC MOTIVATION}

Although the term's first published use was in 1985, SDT's beginning was in 1977 and has continued to develop and be refined into the present day. Breaking the accepted behaviorism theory of rewarding actions and behaviors in order to entice them being repeated, Deci and Ryan (1985), both psychologists, wanted to explore why people do the things that they do. Their focus was mainly concerned with people's motivation for doing something. In short, IM is 
concerned with doing something for its own sake, whereas extrinsic motivation is concerned with doing something for a reward or praise. IM is more appealing to educators because it tends to produce desirable behaviors such as doing more challenging tasks, trying harder, and persevering through difficulties (Ferrer-Caja \& Weiss, 2002). Fundamentally, SDT and IM are concerned with three main psychological aspects: autonomy, competence, and relatedness.

In their 1985 book, where they first used the phrase Self-Determination Theory, Deci and Ryan contended that in order for people to reach their highest possible potential, be it in work, education, or sports, certain psychological needs must be met-autonomy, competence, and relatedness (O'Hara, 2017). These psychological needs are all related to IM, which is inherent in all people. Although IM is inherent, it wanes during elementary and middle-school years (Crow, 2006). Educators should be concerned with maintaining or reactivating student IM. The theory has reached the world over and continues to inspire more research and debate among academics, and helps educators help learners.

\section{METHODOLOGY}

This review of literature is concerned with how CL and IM "fit together." That is, how do the two separate theories complement each other in order to maximize learners' learning? In researching the vast amount of literature, it became evident that a multitude of research studies have been conducted addressing this matter. To gain an objective perspective, the literature focused on for this literature review is very diverse-from several different countries, with no course subject or education level given preferential treatment. Some studies had very small sample sizes, while others contained very large ones. Other studies had a general interest in how CL and IM interact in a particular subject, and still others were interested in how they interact while teaching a very specific task. The three main levels of education were found in the literature: primary, secondary, and tertiary.

\section{Cooperative Learning's Strengths and Weaknesses}

Attention should first be given to why CL should be of interest to educators. Examining the benefits and drawbacks of CL, Ghufron and Ermawati wrote, "The Strengths and Weaknesses of CL and Problem Based Learning in EFL Writing Class: Teachers and Students' Perspectives" in 2018 for the International Journal of Instruction. The purpose of their research was to compare the educators and learners' opinion about the pros and cons of instruction in two different pedagogies: project-based learning and CL. For purposes of this literature review, attention will only be given to the CL aspect of their study.

This two-week qualitative study was conducted in an English as a Foreign Language (EFL) writing class (composed of first-year through last-year undergraduate students) in Indonesia. The researchers used a purposeful sampling technique to choose one out of 11 teachers in the English Education Department at a university - basing their decisions on classroom experience using $\mathrm{CL}$ and willingness to participate in the study. They used intensity sampling to select 30 students (from an unstated number of possible students) whom they felt would be ablest to provide feedback with the most useful information. The study was conducted using nonparticipant classroom observation, in-depth interviews with the teacher and some of the students (unstated how many) the student interviews were based on responses given during the teacher interviews, and a five-point Likert-style student questionnaire.

After analyzing the interview and questionnaire data, the teacher and students' results were reported separately. The teacher listed increased student engagement, motivation, responsibility, and interaction as the benefits of CL; timeconsuming, demanding of teacher engagement, and classroom control were the stated drawbacks of CL. One student interview (unstated how many were interviewed) listed an increase in self-confidence and motivation, as well as a reduction in nervousness, as the benefits of CL; another student stated that CL can be confusing for the students as a drawback. Based on the questionnaire, benefits of CL are that it increases student confidence, motivation, and responsibility in learning; drawbacks of CL are that it can be confusing and that groups can be unbalanced (not having a good mixture of student abilities based on a random assignment of groups). Both the strengths and weaknesses found in this study support findings in several previous studies.

The researchers' conclusion was that CL has both strengths and weaknesses, citing the ones discovered in the study. Overall, this study did not prove anything, but instead, gathered the opinions of a teacher and students who used CL. Perhaps a better study would have been to compare the opinions of more than one teacher and class, using control (not receiving CL) and treatment groups (receiving CL). Other concerns are the participant selection and reporting (which was not clearly stated), the teacher sample size $(\mathrm{N}=1)$, and the short duration of the study (two weeks). Still, as the results supported previous studies, and independent studies have had similar results, this study's results can be considered supportive of general findings.

\section{Why Intrinsic Motivation Should be of Interest to Educators}

There is a plethora of pedagogies and teaching strategies available for educators to utilize, but perhaps considerations for IM should be integrated into any teaching style. In the quantitative study conducted by Froiland and Worrell, "Intrinsic Motivation, Learning Goals, Engagement, and Achievement," published in 2016, in Psychology in the Schools, IM's significance was examined. The study's purpose was to examine how learning goals, IM, and engagement work together in student achievement in high school. For purposes of this literature review, IM will be given primary attention. 
The participants consisted of 1,575 students $(53 \%$ female) from a high school in San Francisco (all students were given the survey, but not required to complete it); all four grade levels were involved, almost in equal proportions of 25\%. IM was measured using four seven-point Likert-style questions, which were taken from five-point Likert-style questions developed by Skinner et al (2008). There were no control or treatment groups, but instead, this study conducted by distributing and collecting surveys. The results found, in addition to other items concerned with the researchers, that IM was significantly related to the other two aspects-it was associated with engagement in a strong, positive manner, and with learning goals in a moderate, positive manner.

This study supported previous studies' findings - that IM has a positive association with engagement (Walker et al., 2006), and that IM has a positive association with achievement (Froiland \& Oros, 2014). Of particular note in this study, a positive, indirect association was found with GPA via engagement, supporting that IM leads to engagement (Ryan \& Deci, 2009). Based on the study's findings, the researchers contend that IM is key to sustained engagement, and supports high school completion. Overall, this study shows that IM is an integral aspect of student success.

\section{International Studies Regarding CL's Effect on IM}

Six studies investigating CLs effect on IM are the focus of this literature review. To make the results as generalizable as possible on a global level, this author selected studies that were conducted in Europe and Asia, with participants at the primary, secondary, and tertiary levels. Other parts of the world were not included in this focused analysis due to either a lack of relevant studies on CLs effect on IM, or a plethora of them, such as North America-whose results from many research studies are supported in the included literature. Each study is analyzed regarding its purpose or investigated problem, methodology, participants, results, conclusions, and implications. This author's opinion of some aspects of the study are offered when potentially contentious.

In the first study discussed in this literature review, the researchers investigated if CL affects IM, and the topic was researched while doing a specific learning task. The research study, "The Collaboration of Cooperative Learning and Conceptual Change: Enhancing the Students' Understanding of Chemical Bonding Concepts," conducted by Eymur and Geban in 2017, was published in the International Journal of Science and Math Education. Using a randomly assigned control group (of 37 students) and treatment group (of 35 students) from two already-established $9^{\text {th }}$ grade Chemistry classes in a randomly chosen Turkish public high school, this mixed-method research study's purpose was to investigate CL's effect on conceptual change instruction on students' understanding of chemical bonding, which was prompted by the lack of such research.
The two groups of $729^{\text {th }}$ graders (32 male and 40 female) were taught by the same teacher, and assumed to be of relatively the same socioeconomic status and educational background. To investigate, a researcher-created pre-test and post-test was given to all of the students to assess their content knowledge, as well as semi-structured interviews (with 12 students - six from each group) at the conclusion of the sixweek study, and classroom observations were conducted throughout; the control group was taught by traditional chemistry instruction and the treatment group was taught using CL. The qualitative results (from interviews) showed that students in the treatment group were much more able to conceptually explain the material taught, and among other things, explained that their motivation to learn increased during the group work.

In part, the conclusion of this study supported previous seminal research studies, in that students reported the treatment increased their learning motivation. A couple potential concerns of this study are the small sample size of the treatment group $(\mathrm{N}=35)$ and its short duration (six weeks).

In a Spanish study, researchers examined how CL effects IM in a larger class setting. The article, "Effects of Cooperative-Learning Interventions on Physical Education Students' Intrinsic Motivation: A Systematic Review and Meta-Analysis" written by Fernandez-Espinola et al., was published in the International Journal of Environmental Research and Public Health in 2020. Using a sample size of 1020 , this study's purpose was to measure CL's effect on IM in physical education students in Spain. Five studies were conducted among the 1020 participants (518 in the treatment group; 502 in the control group): two in primary school, two in high school, and one in university. The treatment group received CL instruction and the control group received traditional instruction. The different studies lasted between three weeks and six months, using between six and 30 treatment sessions. Among the different studies, there were several CL structures and techniques used with the treatment group, mostly in one-hour sessions.

The Perceived Locus of Causality Scale, translated into Spanish, was used to evaluate the motivation levels of all participants, one part being IM in particular. The results mostly showed that CL can improve IM in physical education students; one of the five treatment group results showed a decrease in IM. The decrease was found in the primary school treatment group with the youngest participants (average age was 8.4 years) - this created the question if CL is better suited for older students who are able to grasp the idea of CL and can learn to work cooperatively.

The main conclusion was that CL can increase IM. This study was probably too broad in its scope-from young primary through university students. Another potential problem of this study was that there were several CL strategies used among the different groups, raising potential reliability concerns. The researchers suggested doing further 
research with more explanations of CL techniques used. They also suggested that students have their autonomy developed before intervention. Overall, this study does not provide reliable or generalizable results.

In another a Spanish study, more focused than the previously discussed study, Estrada et al. conducted a sixmonth quantitative study which was published in 2019 in Psicothema. In part, its purpose was to investigate if $\mathrm{CL}$ increases IM in physical education, assuming the pattern that CL leads to an increase in relatedness, and that relatedness leads to an increase in IM (which then leads to an increase in intention to do sport, but this final aspect will not be discussed in this literature review).

The researchers created control $(\mathrm{n}=190 ; 101$ boys and 89 girls) and treatment ( $\mathrm{n}=182 ; 96$ boys and 86 girls) groups from four high schools of convenience. To evaluate CL, they used a pre-test and post-test of an adapted, approved translation of the Co-operative learning subscale from the Perceived Motivational Climate in Sport Questionnaire (PMCSQ-2) by Newton, Duda, \& Yin (2000), which consisted of four five-point Likert-style questions. To evaluate IM, they used the Perceived Locus of Causality scale (PLOC; Goudas, Biddle, \& Fox, 1994), which was translated and validated for use in a Spanish PE class.

Both groups were determined to start at the same level using a MANOVA. After treatment, the results showed that the treatment group scored higher than the control group in every category analyzed, using univariate analyses. Of specific interest to this literature review, the treatment group showed an increase in learners' perception of $\mathrm{CL}$, an increase in relatedness, and an increase in IM.

The results of this study seemed to show that CL increases IM. Based on the sample size $(\mathrm{N}=372)$ and duration of the study (six months), the results are probably reliable and generalizable in Spain. Similar studies in other countries could increase the generalizability. Overall, this study could help contribute to the larger body of knowledge concerning CLs effect on IM.

Investigating CLs effect on IM in a Vietnamese university classroom, the study "Does Cooperative Learning Increase Students' Motivation in Learning?" conducted by Tran was published in 2019, in the International Journal of Higher Education. Having identified a problem that much research regarding CL has been conducted in western educational settings, this quantitative study's purpose was to evaluate its effectiveness in an eastern educational setting.

This study used a sample of 72 second-year Vietnamese university students in already-established, equally-divided classes, so that the control and treatment groups each had 36 students (with a female to male ratio of 27:9 and 29:7, respectively) with an average age of a little over 19 years. The groups were randomly chosen to be control (to receive lecture-style learning) and treatment (to receive
CL), and taught the same content material by the same lecturer, for the same duration of time in the afternoon, in the same classroom, over a 9-week period. Both groups took a pre-test on motivation, and to assess the intervention, the Pintrich et al.'s four-part motivational scale was used as a post-test - in part, measuring intrinsic goal orientation by using 45 -point Likert-style questions.

The results showed that although there was no significant difference between the groups on the pre-test on motivation, there was significant difference between the groups on the motivational components of the post-test (determined by t-test analyses). Regarding CL's effect of enhancing learners' motivation, this study supported previous studies (Doymus, Karacop, \& Simsek, 2010; Sahin, 2010). The conclusion drawn was that CL could be more beneficial than lecture-style learning for Vietnamese students. With a sample size of only 72 university students, the results cannot be reliably generalized, and the researcher of this study suggested doing more research at different educational levels in Vietnam.

In another study conducted in Asia, Ning and Hornby wrote, "The impact of cooperative learning on tertiary EFL learners' motivation" in 2014 for Educational Review. Specifically concerned with CL's effect on improving English language learners' motivation at a university in northern China, this study included non-English major participants from 14 different subject majors. From 30 first-year English as a Foreign Language classes at the university, the researchers randomly selected two to participate, and the particular groups were randomly assigned - the treatment group (receiving CL instruction) had 52 participants (24 male and 28 female); the control group (receiving traditional instruction) had 48 participants (31 male and 17 female). All of the participants had an average age of 19.5 years and had studied English for an average of 8.0 years.

The Language Learning Orientations Scale (LLOS) was used as a pre-test and post-test at the beginning and the end of the 18-week study. In part, the LLOS measured IM using 10 7-point Likert-style questions which was made available in Chinese and English. The results showed that the treatment group's IM increased significantly whereas the control group's IM did not.

This study supports previous research findings (Dörnyei 1997, 2001; Holt 1993; Jacobs and Goh 2007; Johnson and Johnson 2003; Johnson, Johnson, and Holubec 1998; Kagan and Kagan 2009; McCafferty, Jacobs, and DaSilva Iddings 2006; Slavin 1995), finding that CL increases IM. The researchers attribute the increase to the satisfaction of competence, autonomy, and relatedness - the basic foundation of SDL. Although the sample sizes of 52 and 48 are not large, this study's findings support and echo previous research regarding CL's effect on IM.

In a different study conducted in China, the article "Promoting Learner Autonomy Through Cooperative 
Learning" was written by Shi and Han, and published in 2019 in English Language Teaching. Identifying learner autonomy as a key factor of language learners' attitudes and motivation of learning, one of this study's purposes was to investigate if CL promotes learner autonomy. The participants, 168 18-20 year old first-year college students (non-English majors), from three different established classes, were taught by the same lecturer with the same materials and periods (assumed to be referring to lesson duration), over the course of the onesemester study. Control and treatment groups were not used in this study. The study involved participants using CL to share news stories in English (and report in English).

The researchers created an online questionnaire which included, in part, six 5-point Likert-style questions to measure learners' attitude and motivation in regards to CL118 of the participants (46 male and 72 female) completed it. The results showed that CL helped improve and increase students' learning attitude, interest, and motivation. Due to students' lack of interest in English-reported news after the semester ended, the researchers of this study emphasized that educators should try to develop learner autonomy more as researchers (Benson, 2005, 2011; Cotterall, 1995; Voller, 1997; Xu, 2007) previously contended.

The conclusion reached by this study is that cooperative group learning can help support learner autonomy, a key aspect of IM. Although it seems lacking, a control group in this particular study would not have been possible because by nature, the task participants were expected to do relied on the structure of CL. Overall, this study could have been made more reliable if a control group had been studied.

\section{A Concern Regarding Using Student Rewards}

Extensive previous research has shown that rewards have positive effects on CL as well as negative ones. This is of particular interest concerning IM since it is difficult to valuate IM's impact on student success if rewards (extrinsic motivation) are involved. Interested in the effects of removing rewards after having already been established, Sears and Pai conducted the study "Effects of Cooperative Versus Individual Study on Learning and Motivation After RewardRemoval," which was published in 2012, in The Journal of Experimental Education, to investigate the scenario. In part, the purpose of the study was to examine the effects of reward and reward-removal in cooperative groups and individual contexts.

Forty random participants ( 25 male, 15 female) from a large university in the USA, with little or no music reading ability, were assigned to one of four groups ( $\mathrm{N}=10$ for each): individuals without reward/reward-removal; pairs without reward/reward-removal. The study was conducted in two phases. During Phase 1, the individuals and pairs without reward completed the learning material, took a posttest to measure the learned content, and completed a five-question Likert-style paper survey based on the Intrinsic Motivation
Inventory (Deci \& Ryan, 2009). These groups repeated the same procedure in Phase 2. During Phase 1, the individuals and pairs with reward-removal completed all the same steps as the no-reward groups, but at the start, were told they would each receive US\$5 if they earned $75 \%$ or higher on the posttest; at the beginning of Phase 2, they were told the reward would not be available for the second posttest. All participants received compensation for their time and participation in the study.

The results from Phase 1 found that the individual/pairs who received the reward incentive (the reward-removal group) scored significantly higher on the posttest than the no-reward groups, as well as motivation; no significant difference was found between individuals and pairs. Using the same analysis, the results from Phase 2 found no significant differences between the reward/reward-removal groups, but did find a significant difference between the individuals and pairs in the reward-removal groups. There were no significant differences among the motivation results in either phase.

The conclusions drawn by the researchers were that when offered a reward, everyone will work harder, regardless whether learning individually or cooperatively. After removing a reward that was previously given, for the same performance expectations, individuals performed much lower on the posttest than when offered a reward, whereas CL groups (the pairs) did not drop as much as the individuals - of particular interest and surprise in this study, was that one of the pairs actually increased performance after the reward was removed. Interestingly, all 40 participants' self-reported motivation was about the same at the end of each phase.

The implications of this study were that more studies should be conducted in this matter. It seems that according to this study, rewards may potentially hinder results in CL, even though self-perceived motivation seems unaffected by the participants. This study's small groups sizes $(\mathrm{N}=10)$ may not be generalizable; only having two phases may also prevent generalizability. Overall, this was a noteworthy study which prompts the need for further research regarding lack of rewards in CL.

\section{Implementing Cooperative Learning in the Classroom}

As this literature has shown, CL can have a positive effect on IM, specifically, by increasing it. However, there are also studies which show results to the contrary. There are several factors which could contribute to the negative results. It is this author's opinion, as well as numerous researchers, that one main cause of this is improper implementation of CL in the classroom, or improper teacher training in how to implement CL. Randomly putting learners together for an activity is not CL (Slavin, 2014). CL is not a one-size-fits-all pedagogical practice that can "just work." Even if a teacher has not been trained in how to incorporate $\mathrm{CL}$ in the classroom, Slavin has done a landmark study that most teachers could use to understand how to incorporate $\mathrm{CL}$ in 
their learners' learning. His structure fits CL and IM together well, which if followed, should increase the likelihood of its success. There are five basic elements to observe, which were written in 2014 by Richard Slavin and published in Educational Leadership.

First, interdependent teams must be formed. Ideally, teams should be four learners (or five if there is an odd number) and work together for six to eight weeks. Have teams create a team name and motto or crest, and sit in teams during instruction. Teams should have high, average, and low performing learners of mixed sex/gender and ethnicities (if applicable), so the teacher should form the groups. The teams must understand that they can depend on each other for help, and the teacher must actively observe to ensure that no students are shirking participation or dominating the team.

Second, goals need to be established for the teams. Slavin does not mention who should determine the goal, but to increase autonomy, the teams should create teacherreviewed and approved goals. Slavin suggests giving a reward when the team goal is met, such as a certificate which can be displayed in the classroom. The key with team goals for the teacher, is to evaluate a team's achievement and each individual's input to the achievement.

Third, individual accountability must be ensured. This is the element that is probably the most difficult to implement. This is where the concept previously mentioned in this literature review comes into play-that every group member must succeed in order for the team to succeed. The team goal must require active participation from all team members. Explain to the learners why it is important for everyone to actively participate in order to get their involvement. There are particular techniques to help achieve this element. An important aspect for the teacher to keep in mind is not to step in, but let the teams do the cooperative tasks.

Fourth, communication and problem-solving skills must be taught first. If learners are expected to help each other learn, they must be taught how to effectively communicate and solve problems autonomously. This element was mentioned previously in this literature review as a researcher's suggestion. More than a suggestion, it is a logical necessity.

Fifth, CL is not a stand-alone pedagogy, but a teaching technique. CL cannot be the entire lesson, but an aspect of each lesson. The teacher must still give instruction by lecturing, utilizing technology, showing videos, and other modes. CL should be used instead of independent work, which can be boring or frustrating for some, or too easy for others. Use the well-formed teams to work autonomously and interdependently.

The implications of this structure is that CL will be used effectively to increase IM, and over time, the increased IM will lead to more effective CL. The results rest with the teacher's efforts and ability to prepare learners to use CL appropriately.

\section{SUMMARY}

The cases presented in this review of literature show that CL increases IM in specific learning tasks, as well as in classes as a whole. CL may not be suitable for young children still learning basic interpersonal skills. Although some thoughtful planning must be done by the teacher, as well as some scaffolding of communication and problem-solving skills, implementing CL in the classroom seems to be an effective teaching technique for increasing student IM. Thoughtful consideration should be given to whether or not to include primary rewards with CL. Appropriate implementation of it is needed to achieve desired results, and formal teacher training in CL could also prove beneficial in it being successful in the classroom.

\section{RECOMMENDATIONS}

In today's classroom, a student-centered approach has proven to be quite effective in achieving learning objectives. By focusing on increasing student IM, educators would be increasing the likelihood of student success for all ability levels. Since CL has been demonstrated to have a positive impact on student IM, CL should be implemented in classrooms. To increase the likelihood of its success, formal teacher training in CL should be obtained, as well as preparing students to use it by scaffolding communication and problemsolving skills.

\section{CONCLUSION}

The benefits of CL have been evidenced by research across nations and decades - its appropriate classroom implementation engages more students more of the time, as compared to traditional lecture-style instruction. CL's success is dependent on appropriate implementation of it. Appropriate classroom implementation is most likely to be successful if teachers are formally trained in using CL. In addition to teacher training, students should also be trained in basic interpersonal communication skills and problem solving skills beforehand. With proper teacher and student training and preparation, implementing CL will most likely be successful in the classroom and beneficial for students, particularly increasing their intrinsic motivation.

\section{REFERENCES}

[1] Baumgardner, C. (2015). Cooperative Learning as a Supplement to the Economics Lecture. International Advances in Economic Research, 21(4), 391-398. https://doi.org/10.1007/s11294-0159545-9

[2] Crow, S. R. (2006). What Motivates a Lifelong Learner? School Libraries Worldwide, 12(1), 22-34.

[3] Deci, E. L., \& Ryan, R. M. (1985). Intrinsic motivation and selfdetermination in human behavior. New York, NY: Plenum.

[4] Deci, E. L., \& Ryan, R. M (2009). Intrinsic motivation inventory. Retrieved from http://www.psych.rochester.edu/SDT/ measures/IMI scales.php 
[5] Deutsch, M. (1949). A Theory of Co-operation and Competition. Human Relations, 2(2), 129-152. https://doi.org/10.1177/001872674900200204

[6] Estrada, J. A. C., González-Mesa, C. G., Llamedo, R., Martínez, B. S., \& Pérez, C. R. (2019). The impact of cooperative learning on peer relationships, intrinsic motivation and future intentions to do sport. Psicothema, 31(2), 163-169. http://dx.doi.org/10.7334/psicothema2018.305

[7] Eymur, G., \& Geban, Ö. (2017). The Collaboration of Cooperative Learning and Conceptual Change: Enhancing the Students' Understanding of Chemical Bonding Concepts. International Journal of Science \& Mathematics Education, 15(5), 853-871. https://doi.org/10.1007/s10763-016-9716-Z

[8] Ferrer-Caja, E., \& Weiss, M. R. (2002). Cross-Validation of a Model of Intrinsic Motivation with Students Enrolled in High School Elective Courses. The Journal of Experimental Education, 71(1), 41-65. https://doi.org/10.1080/00220970209602056

[9] Fernández-Espínola, C., Robles, M. T. A., Collado-Mateo, D., Almagro, B. J., Viera, E. C. \& Fuentes-Guerra, F. J. G. (2020). Effects of Cooperative-Learning Interventions on Physical Education Students' Intrinsic Motivation: A Systematic Review and Meta-Analysis. International Journal of Environmental Research and Public Health, 17(4451), 4451. https://doi.org/10.3390/ijerph17124451

[10] Frey, B. (2018). The SAGE encyclopedia of educational research, measurement, and evaluation (Vols. 1-4). Thousand Oaks, CA: SAGE Publications, Inc. http://dx.doi.org/10.4135/9781506326139

[11] Froiland, J. M., \& Worrell, F. C. (2016). Intrinsic Motivation, Learning Goals, Engagement, and Achievement in a Diverse High School. Psychology in the Schools, 53(3), 321-336. https://doi.org/10.1002/pits.21901

[12] Ghodbane, T., \& El Achachi, H. H. (2019). Narrowing the Achievement Gap between EFL Students in Oral Expression through Cooperative Learning. Arab World English Journal, 10(2), 365-378.

[13] Ghufron, M. A., \& Ermawati, S. (2018). The Strengths and Weaknesses of Cooperative Learning and Problembased Learning in EFL Writing Class: Teachers and Students'
Perspectives. International Journal of Instruction, 11(4), 657-672. https://doi.org/10.12973/iji.2018.11441a

[14] Johnson, D. W., \& Johnson, R. T. (1984). Structuring Groups for Cooperative Learning. Organizational Behavior Teaching Review, 9(4), 8-17. https://doi.org/10.1177/105256298400900404

[15] Johnson, D.W., \& Johnson, R.T.,(2007). The Cooperative Learning Center at the University of Minnesota. http://www.cooperation.org.

[16] Ning, H., \& Hornby, G. (2014). The Impact of Cooperative Learning on Tertiary EFL Learners' Motivation. Educational Review, 66(1), https://doi.org/10.1080/00131911.2013.853169

[17] O'Hara, D. (2017, December 18). The intrinsic motivation of Richard Ryan and Edward Deci. American Psychology Association. https://www.apa.org/members/content/intrinsicmotivation

[18] Panitz, T. (1999). The Motivational Benefits of Cooperative Learning. New Directions for Teaching \& Learning, 1999(78), 59. https://doi.org/10.1002/tl.7806

[19] Sears, D. A., \& Pai, H.-H. (2012). Effects of Cooperative Versus Individual Study on Learning and Motivation After RewardRemoval. Journal of Experimental Education, 80(3), 246-262. https://doi.org/10.3102/00028312018003273

[20] Shi, W., \& Han, L. (2019). Promoting Learner Autonomy through Cooperative Learning. English Language Teaching, 12(8), 30-36. https://doi.org/10.5539/elt.v12n8p30

[21] Skinner, E., Furrer, C., Marchand, G., \& Kindermann, T. (2008). Engagement and disaffection in the classroom: Part of a larger motivational dynamic? Journal of Educational Psychology, 100, 765-781.

[22] Slavin, R. E. (1980). Cooperative Learning. Review of Educational Research, 50(2), 315-342. https://doi.org/10.3102/00346543050002315

[23] Slavin, R. E. (2014). Making Cooperative Learning Powerful. Educational Leadership, 72(2), 22-26. https://doi.org/10.1371/journal.pone.0181336

[24] Tran, V. D. (2019). Does Cooperative Learning Increase Students' Motivation in Learning? International Journal of Higher Education, 8(5), 12-20. https://doi.org/10.5430/ijhe.v8n5p12 